\title{
Determination of Main Plant Sterols in Turkish Bread Wheat (Triticum aestivum $L$.) by GC-MS
}

\author{
Halil Erdem¹, Yener Kortan Tosun², Orhan Hazer³, Mohammed Akkbik* ${ }^{4 *}$ \\ ${ }^{I}$ Soil Science and Plant Nutrition Department, Faculty of Agriculture, Gaziosmanpasa University, 60240 Tokat, Turkey \\ ${ }^{2}$ Plant and Animal Production Department, Vocational School, Bozok University, 66100 Yozgat, Turkey \\ ${ }^{3}$ Department of Chemistry, Faculty of Arts and Sciences, Bozok University, 66100 Yozgat, Turkey \\ ${ }^{4}$ Science and Technology Application and Research Center, Bozok University, 66100 Yozgat, Turkey
}

\begin{tabular}{l}
\hline A R T I C L E I N F O \\
Research Article \\
Received 17 October 2016 \\
Accepted 24 May 2017 \\
\hline
\end{tabular}

Keywords:

Turkish bread wheat

$\beta$-sitosterol

Campesterol

Stigmasterol

GC-MS

Optimization \& validation

\begin{abstract}
A B S T R A C T
Plant sterols are belong to triterpenes family of natural products which includes more than 200 different types of plant sterols and more than 4000 other types of triterpenes. The optimization of method, specially the derivatization step as well as the corresponding analytical validation, is the main goal of this study. The optimum temperature, time and reagent volume of derivatization step were obtained at $60^{\circ} \mathrm{C}, 60$ minutes and $50 \mu \mathrm{L}$, respectively. A rapid and sensitive gas chromatographic-mass spectrometric method was developed and validated for quantitative analysis of the most common plant sterols ( $\beta$-sitosterol, campesterol and stigmasterol) in 20 Turkish bread wheat cultivars using GC-MS-SIM. Separation of $\beta$-cholestanol (I.S), campesterol, stigmasterol and $\beta$-sitosterol was achieved on Rxi (5Sil MS) column $(60 \mathrm{~m} \times 0.25 \mathrm{~mm})$. The limits of detection for $\beta$-sitosterol, campesterol and stigmasterol were $0.074,0.054$ and $0.064 \mathrm{mg} \mathrm{kg}^{-1}$, respectively with RSD $\leq 0.66 \%$. The obtained concentrations of campesterol, stigmasterol and $\beta$-sitosterol from 20 Turkish bread wheat cultivars ranged from: 15.30 to $76.02,4.27$ to 23.23 and 303.21 to $682.66 \mathrm{mg} \mathrm{kg}^{-1}$, respectively.
\end{abstract}

Corresponding Author:

E-mail: mohammed.akkbik@bozok.edu.tr

DOI: https://doi.org/10.24925/turjaf.v5i7.710-719.1035

\section{Introduction}

Wheat has been a major food source in the human diet for more than 8000 years in Europe, Anatolia, west Asia and north Africa (Shewry, 2009). Wheat is the most important food crop grown worldwide and one of the 'big three' cereal crops, with over 600 million ton being harvested annually (Valsta et al., 2004; Shewry, 2009). Bread wheat is an important source of plant sterols in the human diet (Alignan et al., 2009). Clifton et al. (2004) and Valsta et al. (2004) reported that even if the plant sterols level in cereals is lower than oilseeds, cereals remain the major source of natural plant sterols in the human diet due to the large amounts consumed daily. The class of sterols known as plant sterols is found mainly in plant cell walls and membranes as a free or as an esterified form (with fatty and phenolic acids) or as steryl glycosides or as acylated steryl glycosides (Jeong and Lachance, 2001; Moreau et al., 2002; Ruibal-Mendieta et al., 2004; Jiang and Wang, 2005; Cunha et al., 2006; Lagarda et al., 2006). Plant sterols play an essential role in the regulation of membrane fluidity and permeability by affecting the proteins associated to membranes (Breinholder et al., 2002). Moreover, they are precursors of brassinosteroids and are involved in embryogenesis (Alignan et al., 2009). Plant sterols and cholesterol are polycyclic steroid compounds with similar chemical structure (Johnsson et al., 2003; Lagarda et al., 2006; Dulf et al., 2009). The major plant sterols is belonging to the group of 4-demethylsterols is included campesterol (24- $\alpha$-methylcholesterol), $\beta$-sitosterol (24- $\alpha$ ethylcholesterol) and stigmasterol $(\Delta 22, \quad 24-\alpha-$ ethylcholesterol) which is generally found in the lipids of cereals (Dutta and Normen, 1998; Breinholder et al., 2002; Johnsson et al., 2003; Phillips et al., 2005; Lagarda et al., 2006; Santos et al., 2007; Mitei et al., 2009). $\beta$ sitosterol is generally the dominant form $(62 \%)$, followed by campesterol $(21 \%)$ and stigmasterol $(4 \%)$ (Lagarda et al., 2006). The plant sterols present similar amounts than cholesterol in our diet (Grandgirard et al., 2004). Plant sterols are less efficiently absorbed compared to cholesterol ( $\beta$-sitosterol absorption in humans ranges from 1.5 to $10 \%$ while absorption of cholesterol ranges from 20\% to 60\%) (Dutta and Appelqvist, 1997; Phillips et al., 2005; Lagarda et al., 2006). Plant sterols have bioactive properties such as anti-inflammatory, antibacterial, antifungal, anti-ulcerative, antioxidant and antitumoral activities (Rozenberg et al., 2003; Cunha et 
al., 2006). Recent reports claim that plant sterols have significant effects in the treatment of benign prostatic hyperplasia, rheumatoid arthritis, allergies, and stress related illness, and inhibit the development of colon cancer (Jeong and Lachance, 2001; Rozenberg et al., 2003; Phillips et al., 2005). Additionally, it has been demonstrated that plant sterols have the potential to decrease the level of serum low density lipoproteincholesterol (LDL-C) by reducing intestinal cholesterol absorption which protects against cardiovascular diseases. This has led to the development of functional foods enriched with plant sterols (Dutta and Normen, 1998; Kalo and Kuuranne, 2001; Grandgirard et al., 2004; Jiang and Wang, 2005; Cunha et al., 2006; Lagarda et al., 2006). Plant sterols esters can also be recognized as safe (GRAS) for use as an ingredient in vegetable oil spreads at a level up to $13.3 \%(\mathrm{w} / \mathrm{w})$. In Europe, the Scientific Committee on Food approved the use of plant sterols esters in yellow spreadable fats at a maximum level of $8 \%$ of free sterols (Lagarda et al., 2006).

Turkey is one of the major wheat producing countries in the world (Cakmak et al., 1996). In the 2011-2016 period, Turkey produced around 21.03 million tons of wheat (FAO, 2017; USDA, 2016). The main wheatproducing areas in Turkey are located in central, east and southeastern of Anatolia, north and south of Marmara, Polatlı, Hatay, Aegean, Aydın, Çukurova and other regions (USDA, 2016). The average daily consumption of wheat and wheat products by an average Turkish person is about two times as high as most Western countries (Giray et al., 2007). Daily consumption of these products is estimated to be approximately $400 \mathrm{~g}$ and this amount corresponds to almost $50 \%$ of daily diet (Giray et al., 2007). The interest for plant sterols in bread wheat is related to the fact that they rank high among dietary sources of micronutrients just behind vegetable oils, cereal products and derived products thereof (Rozenberg et al., 2003). The increasing public interest to determine the distribution of plant sterols in different types of wheat has provided impetus to review existing chromatographic methods (Nurmi et al., 2012). Derivatization, usually trimethylsylilation in the case of plant sterols, is compulsory for GC analysis due to the glycoside forms are not sufficiently volatile without derivatization (Abidi, 2001; Rozenberg et al., 2003; Ruibal-Mendieta et al., 2004). The application of GC-MS on plant sterols characterization has already been demonstrated in wheat grain after saponification, allowing the identification of free and released (formerly esterified) stigmasterol, $\beta$ sitosterol and campesterol (Abidi, 2001; Nurmi et al., 2012).

The most common methods for determination of plant sterols involve extraction of the lipid fraction from sample followed by alkaline hydrolysis (saponification), extraction of the nonsaponifiables, derivatization of plant sterols, separation and quantification of the plant sterols derivatives as free plant sterols by gas chromatography using a capillary column (Toivo et al., 2000; Abidi, 2001; Ruibal-Mendieta et al., 2004). The purpose of this study was to develop a simple, reliable, sensitive, selective and an affordable technique. The applicability and specificity of this new method were used to determine the presence of $\beta$-sitosterol, campesterol and stigmasterol in selected fresh samples of bread wheat grown in different locations of Turkey under conventional conditions using GC-MS with the selected ion monitoring (SIM) mode. Mass detection was preferred to identify the different compounds based on their derivatized mass spectra. This approach provides higher sensitivity as compared other GC detectors, such as FID for instance. The present study aims to contribute to the optimization of method, specially the derivatization step as well as the corresponding analytical validation, is the main goal of this study. This is the first report to determine the concentrations of $\beta$-sitosterol, campesterol and stigmasterol in Turkish bread wheat using N,O-bis trimethylsilyl trifluoroacetamide (BSTFA) and trimethylchlorosilane (TMCS), (99:1, v/v) derivatization and silylation reagent with a free pyridine addition.

\section{Materials and Methods}

\section{Collection of Bread Wheat Samples}

Twenty cultivars of bread wheat samples (Triticum aestivum L.) had been collected from various agricultural research institutes in Turkey with a sample size of $25 \mathrm{~g}$ (see Table 1). All samples were ground to a fine powder and stored in the dark at $4^{\circ} \mathrm{C}$ until analysed.

\section{Reagents and Materials}

All chemicals and organic solvents were used at a HPLC grade. Three unsaturates plant sterol standards used were: $\beta$-sitosterol $(\geq 95 \%$ purity, Santa Cruz Biotechnology), stigmasterol ( $\geq 95 \%$ purity, Santa Cruz Biotechnology) and campesterol (65\% purity, SigmaAldrich). $\beta$-cholestanol ( $5 \alpha$-Cholestan-3 $\beta$-ol) saturated plant stanol standard was purchased from Sigma-Aldrich (internal standard, $\geq 95 \%$ purity). Solvents and reagents used for sample preparation were hexane, ethanol and diethyl ether (Merck, Darmstadt, Germany), chloroform (Sigma-Aldrich, Munich, Germany), potassium hydroxide (85\%, Merck, Darmstadt, Germany) and sodium sulfate \& sodium chloride (Merck, Darmstadt, Germany). N,O-bis(trimethylsilyl) trifluoroacetamide (BSTFA) with $1 \%$ trimethylchlorosilane (TMCS) as derivatization and silylation reagent were obtained from Supelco Inc. (Bellefonte, PA, USA). Reverse-osmosis ultrapure type quality water was obtained from Millipore water purification system (DIRECT-Q 8UV, USA).

\section{Plant sterols Extraction Method}

The extraction method of lipid in this study depend on alkaline hydrolysis as one of the most widely method (Kalo and Kuuranne, 2001). Extraction of plant sterols from a various cultivars of Turkish bread wheat samples were performed using a method described by Toivo et al. (2000), Rozenberg et al. (2003) and Francavilla et al. (2010) with slight modification. After the addition of $\beta$ cholestanol $(50 \mu \mathrm{g})$ as an internal standard, one gram of ground wheat was saponified by refluxing in $40 \mathrm{~mL}$ of 
ethanol and $10 \mathrm{~mL}$ of aqueous potassium hydroxide $(500$ $\mathrm{g} \mathrm{L}^{-1}$ ) for 2 hours at $80^{\circ} \mathrm{C}$. The refluxed mixture was then transferred into a separatory funnel, and the reflux bottle was washed with $5 \times 2 \mathrm{~mL}$ of water. The unsaponifiables fraction (the total plant sterols) in the combined solution were then extracted two times: firstly with $20 \times 2 \mathrm{~mL}$ of diethyl ether and secondly with $20 \times 2 \mathrm{~mL}$ of n-hexane. The organic phase (hexane and diethyl ether) was combined, washed three times with $20 \mathrm{~mL} \mathrm{5 \%}$ sodium chloride solution then washed with Milli-Q water until the washing water remained colourless upon addition of phenolphthalein, and organic phase was dried with sodium sulfate. The organic phase was evaporated to dryness using a rotary evaporator (LabTech-EV311, Italy) at $45^{\circ} \mathrm{C}$. The concentrated extract was topped to $10 \mathrm{~mL}$ with chloroform, filtered through a $0.48 \mu \mathrm{m}$ syringe filter.

\section{Optimization of Derivatization Conditions}

The derivatizing temperature and time interval for the derivatization process as well as the volume of silylation reagent were optimized. The optimum temperature was performed with $50 \mu \mathrm{L}$ of BSTFA (with $1 \%$ TMCS) at temperatures of $25,40,50,60$ and $70^{\circ} \mathrm{C}$ for 30 minutes. Then, the optimum time was carried out with five different time periods $(15,30,45,60$ and 90 minutes) at $60^{\circ} \mathrm{C}$ with $50 \mu \mathrm{L}$ of BSTFA (with $1 \%$ TMCS) for the derivatization procedure. While the optimum volume of silylation reagent of BSTFA (with $1 \%$ TMCS) was studied from $10 \mu \mathrm{L}$ to $100 \mu \mathrm{L}$ at $60^{\circ} \mathrm{C}$ for 60 minutes.

\section{Silylation}

A $950 \mu \mathrm{L}$ of an concentrated extract sample or standard sample was transferred into a silanized vial then
$50 \mu \mathrm{L}$ of BSTFA (with 1\% TMCS) as derivatizating and silylating reagent was combined. The mixture was shaken well for $1 \mathrm{~min}$, sample was then incubated at $60^{\circ} \mathrm{C}$ for 60 min (see Figure 1), and finally analyzed by GC-MS after cooling (Santos et al., 2007; Muller et al., 2013).

\section{Gas Chromatography with Mass Spectrometry Detection (GC-MS) \\ GC-MS analyses were performed on an Shimadzu-} QP2010 ultra (Kyoto, Japan) gas chromatography coupled with mass spectrometric detector. Autosampler system and real time analysis software were used for all analyses. One microliter of each sample was injected into the gas chromatography inlet via autosampler. A $60 \mathrm{~m}$ capillary column with a moderately polar stationary phase $(5 \%$ diphenyl and $95 \%$ dimethyl polysilox) was used in the present study for analysis of plant sterols. $\beta$-cholestanol was used as an internal standard. A Restek (Bellefonte, PA, USA) Rxi-5Sil MS capillary column (60 m $\times 0.25$ mm i.d. $\times 0.25 \mu \mathrm{m}$ ) was used for separation. The injector temperature was $260^{\circ} \mathrm{C}$. The temperature program was started at $200^{\circ} \mathrm{C}$ for $1 \mathrm{~min}$ and heated at $15^{\circ} \mathrm{C} \mathrm{min}^{-1}$ to $320^{\circ} \mathrm{C}$, increased by $20^{\circ} \mathrm{C} \mathrm{min}^{-1}$ up to $320^{\circ} \mathrm{C}$. Sample injection was done in split mode with split ratio (50:1) during 1 minute. Helium with high purity (99.999\%) was used as carrier gas at a flow rate of $1.00 \mathrm{~mL} \mathrm{~min}{ }^{-1}$. The mass spectrometer operated in the electron impact mode at ionisation voltage of $70 \mathrm{eV}$, with an ion source temperature of $200^{\circ} \mathrm{C}$. The retention times and the characteristic fragments of plant sterols were determined and recorded by scan mode (total ion monitoring) from $\mathrm{m} / \mathrm{z} 35$ to $\mathrm{m} / \mathrm{z} 500$ with 16.5 minutes as solvent cut time and giving a total run time of 22.0 minutes.

Table 1 The collected 20 Turkish bread wheat cultivars (Triticum aestivum L.).

\begin{tabular}{|c|c|c|c|c|c|}
\hline Name & $\begin{array}{c}\text { Harvest } \\
\text { Year }\end{array}$ & $\begin{array}{c}\text { Harvest } \\
(\mathrm{kg} / \mathrm{da})\end{array}$ & $\begin{array}{c}\text { Protein } \\
\% \\
\end{array}$ & Recommend Areas & Reference \\
\hline Adana 99 & 2015 & $665-735$ & $12.0-13.0$ & coastal areas and southeastern of Anatolia region & Yiğit, 2015 \\
\hline Altınbaşak & 2015 & 703-941 & $12.8-15.4$ & coastal areas and southeastern of Anatolia region & Yiğit, 2015 \\
\hline Bayraktar & 2015 & $300-400$ & $11.0-14.0$ & central Anatolia & Yiğit, 2015 \\
\hline Bezostaja & 2015 & $200-650$ & $13.0-16.0$ & central Anatolia & Yiğit, 2015 \\
\hline Canik 2003 & 2015 & $250-850$ & $10.6-12.6$ & black sea coast and north of Marmara region & Mut et al., 2009 \\
\hline Es 26 & 2015 & $410-550$ & - & - & Imren et al ., 2014 \\
\hline Flamura 85 & 2015 & $350-600$ & $13.0-14.0$ & coastal areas and southeastern of Anatolia region & Aydogan Cifci and Yagdi, 2012 \\
\hline Gökkan & 2015 & $699-955$ & $12.2-13.7$ & coastal areas and southeastern of Anatolia region & Yiğit, 2015 \\
\hline Harmankaya & 2015 & $700-750$ & $12.0-14.0$ & - & Yiğit, 2015 \\
\hline Karatoprak & 2015 & $665-865$ & $10.0-15.0$ & coastal areas and southeastern of Anatolia region & Yiğit, 2015 \\
\hline Kıraç 66 & 2015 & $300-500$ & $12.0-15.0$ & central and eastern of Anatolia regions & Yiğit, 2015 \\
\hline Mesut & 2015 & $240-818$ & $13.2-15.6$ & central Anatolia & Yiğit, 2015 \\
\hline Osmaniyem & 2015 & $632-846$ & $10.0-15.0$ & coastal areas and southeastern of Anatolia region & Yiğit, 2015 \\
\hline Pandas & 2015 & $533-709$ & $12.5-14.8$ & coastal areas and southeastern of Anatolia region & Yiğit, 2015 \\
\hline Sakin & 2015 & $600-750$ & 12.0 & Black Sea coast and south of Marmara region & Mut et al., 2009 \\
\hline Seri & 2015 & $715-1023$ & $11.6-14.9$ & coastal areas and southeastern of Anatolia region & Yiğit, 2015 \\
\hline Soyer & 2015 & $240-560$ & 10.6 & - & Yildirim et al., 2012 \\
\hline Sönmez & 2015 & $250-600$ & $12.0-14.0$ & central and eastern of Anatolia regions & Yiğit, 2015 \\
\hline Tahirova & 2015 & $400-900$ & $12.0-17.0$ & Marmara coastal & Egesel et al., 2009 \\
\hline Yunus & 2015 & $550-820$ & $11.4-13.6$ & central Anatolia & Yiğit, 2015 \\
\hline
\end{tabular}




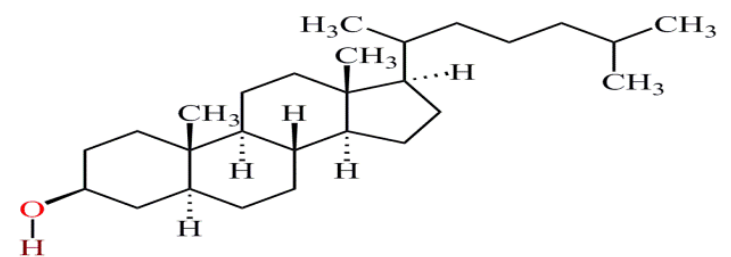

$\beta-C h o l e s t a n o l ~(I . S)$

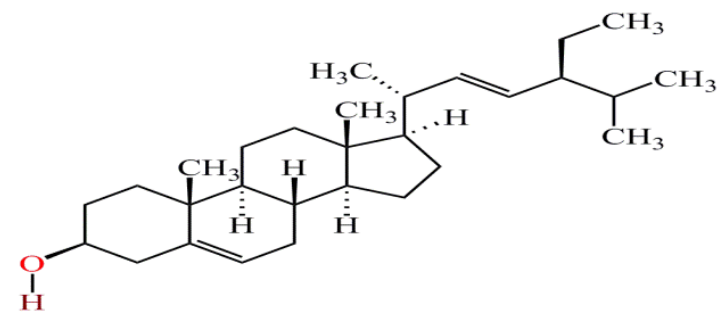

Stigmasterol
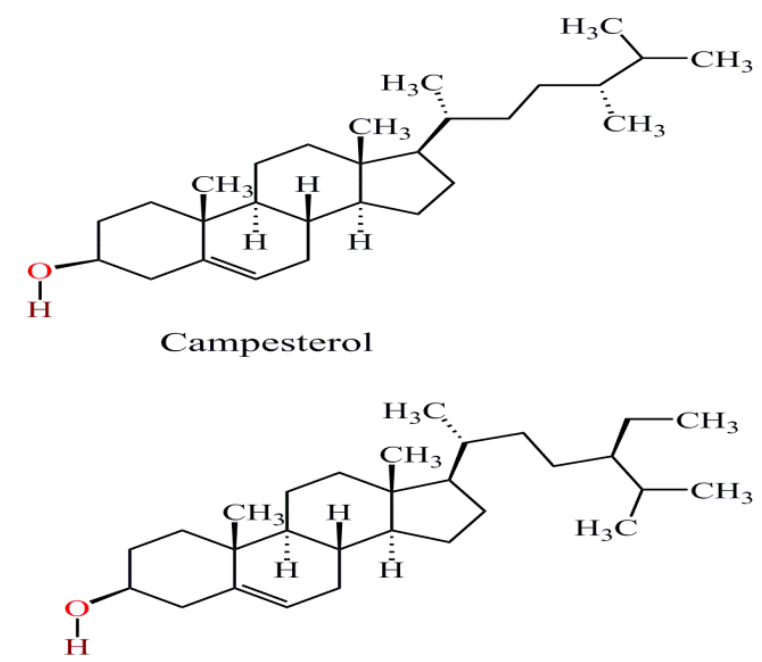

$\beta$-Sitosterol<smiles>C[Si](C)(C)/N=C(/O[Si](C)(C)C)C(F)(F)F</smiles>

N,O-bis-(trimethylsilyltrifluoroacetamide)<smiles>C[Si](C)(C)N=C(O)C(F)(F)F</smiles>

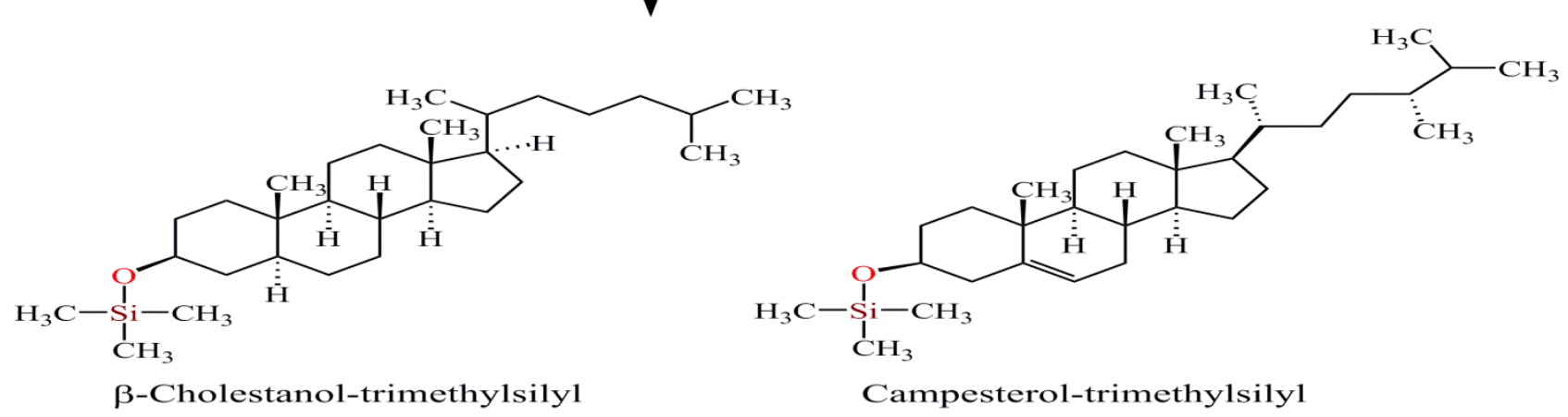

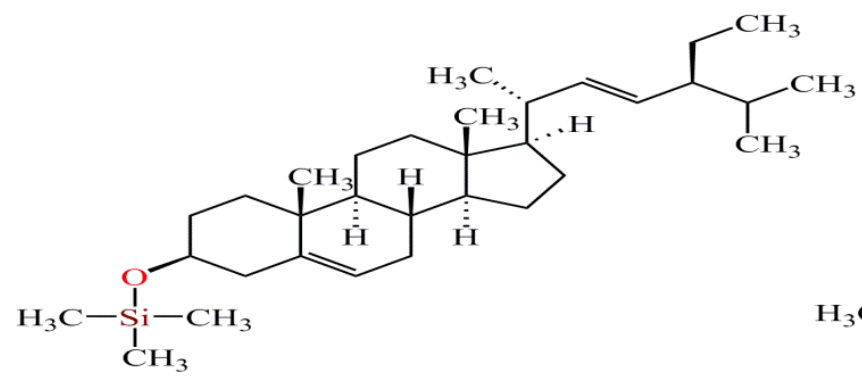

Stigmasterol-trimethylsilyl

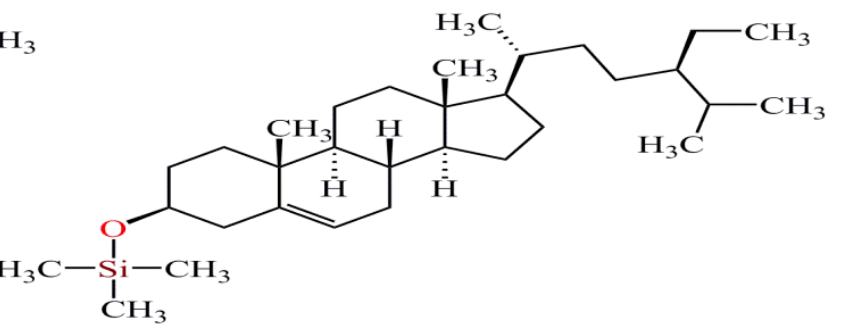

$\beta$-Sitosterol-trimethylsilyl

Figure 1 Derivative the hydroxyl group of main plant sterols using (BSTFA:TMCS, 99:1, v/v) as silylation reagent. 
It is recommendable to perform the analysis by a full scan mode analysis was conducted prior quantification in SIM mode to obtain a general profile of plant sterols. Then, the most three abundant ions for each plant sterol were selected and chosen without apparent crosscontribution or interferences as target ions for the quantification in SIM mode. The following three ions $(\mathrm{m} / \mathrm{z})$ for each plant sterol were then monitored 355, 445, 460 ( $\beta$-cholestanol), 343, 382, 472 (campesterol), 255, 394 and 484 (stigmasterol) and 357, 396, 486 ( $\beta$ sitosterol). Quantification analysis was carried out in selective ion monitoring (SIM) mode using splitless mode during 1 min (see Fig. 2).

Quantification of the most common plant sterols components in Turkish bread wheat was determined by using of $\beta$-cholestanol which was selected as an internal standard. All the GC-MS runs were performed in four replicates.

\section{Validation of the Method}

Validation of the analytical method was performed by assessment of the linearity, sensitivity, specificity and accuracy.

Linearity: Linearity of the method was established by automatic injections of the standard mixture solutions in the investigated ranges from low to high concentrations, and each concentration was repeated four times. Seven different concentrations of campesterol, stigmasterol and $\beta$-sitosterol in chloroform were prepared $(0.25,0.50,0.75$, $1.00,5.00,10.00$ and $25.00 \mathrm{mg} \mathrm{L}^{-1}$ ). The calibration curves were obtained by plotting the ratio of peak area $\left(\right.$ Area $_{\text {plant }}$ sterol $/$ Area $_{\text {I.S }}$ ) versus (Conc. plant $_{\text {sterol }} /$ Conc. $_{\text {I.S }}$ ) between a specific $\mathrm{m} / \mathrm{z}$ ions for each plant sterol and a $\mathrm{m} / \mathrm{z}$ ions for the internal standard $(\beta$-cholestanol at $5 \mathrm{mg}$ $\left.\mathrm{L}^{-1}\right)$.

Sensitivity: The instrumental response sensitivity is given by the slope of the calibration curve. Method with a large slope discriminates small differences in analyte contents. Limit of detection (LOD) and limit of quantitation (LOQ) were determined according to following equation (Song and Wang, 2003):

$$
\mathrm{LOD} \text { or } \mathrm{LOQ}=\mathrm{k}(\mathrm{B} / \mathrm{S})
$$

Where $\mathrm{k}$ is a constant ( 3 for LOD and 10 for LOQ), B is the standard deviation of the analytical signal, and $S$ is the slope.

Specificity: Specificity of the proposed method was evaluated by peak purity curves through resolution factors $\left(\mathrm{R}_{\mathrm{s}}\right)$, peak asymmetry factor $\left(\mathrm{A}_{\mathrm{s}}\right)$ and number of theoretical plates $(N)$. The resolution factor $R_{s}$ was calculated based on Equation 2 (Wang et al., 2003):

$$
\mathrm{R}_{\mathrm{s}}=\left(\mathrm{t}_{2}-\mathrm{t}_{1}\right) /\left(\mathrm{W}_{2} / 2+\mathrm{W}_{1} / 2\right)
$$

Where $t_{1}$ and $t_{2}$ are the retention times of the two components, $\mathrm{W}_{1}$ and $\mathrm{W}_{2}$ are the corresponding widths at the bases of the peaks obtained by extrapolating the relatively straight sides of the peaks to the baseline. The asymmetry factor is a measure of peak tailing and was calculated based on Equation 3 (Sankalia et al., 2007):

$$
\mathrm{A}_{\mathrm{s}}=\mathrm{b} / \mathrm{a}
$$

Where $A_{s}$ is peak asymmetry factor, $b$ is the distance from the point at peak midpoint to the trailing edge, and a is the distance from the leading edge of peak to the midpoint ( $a$ and $b$ were measured at $10 \%$ of peak height). The number of theoretical plates $(\mathrm{N})$ was calculated using Equation 4 (Sankalia et al., 2007):

$$
\mathrm{N}=16 \times\left(\mathrm{t}_{\mathrm{R}} / \mathrm{W}_{1}\right)^{2}
$$

Where, $\mathrm{N}$ is the number of theoretical plates, $t_{R}$ is retention time and $\mathrm{W}_{1}$ is width at the bases of the peak.

Accuracy: The accuracy was evaluated through spiking and recovery testing. The recovery rate of plant sterols at three different fortification levels (1.00, 5.00 and $25.00 \mathrm{mg} \mathrm{L}^{-1}$ ) was evaluated in order to assess the extraction efficiency of the proposed method using external standards addition.

Statistics: All GC-MS analysis were performed in four replicates. The results were expressed as mean \pm standard deviation $(\mathrm{m} \pm \mathrm{SD})$.

\section{Results and Discussion}

\section{Optimization of the Derivatization Conditions}

The optimization of the derivatization conditions were done using the SCAN mode in order to quantify the plant sterols, SIM (selected ion monitoring) mode was then chosen the specific ion for quantification was selected and marked bold for each plant sterol. The following three ions $(\mathrm{m} / \mathrm{z})$ for each plant sterol were then monitored 355 , 445, 460 ( $\beta$-cholestanol), 343, 382, 472 (campesterol), 255,394 and 484 (stigmasterol) and 357, 396, 486 ( $\beta$ sitosterol).

Derivatization is known as the fundamental step since it allows the transformation of glycoside form of plant stanols determined as free plant sterols (Abidi, 2001; Rozenberg et al., 2003; Ruibal-Mendieta et al., 2004). Thus, derivatization temperatures, times and reagent volume were evaluated on selected Turkish bread wheat sample (Adana 99) to optimize the methodology. The results of the optimization procedures are summed up in Table 2.

\section{Validation of the Method}

Linearity (calibration curve: The linearity of analytical procedure for three plant sterols was assessed by spiking seven different concentrations of campesterol, stigmasterol and $\beta$-sitosterol in chloroform were prepared at $0.25,0.50,0.75,1.00,5.00,10.00$ and $25.00 \mathrm{mg} \mathrm{L}^{-1}$ with four replicate $(n=4)$. The chromatographic responses were found to be linear over an analytical range of $0.25-$ $25 \mathrm{mg} \mathrm{L}^{-1}$, quite satisfactory and reproducible with time. The linear regression equation was calculated by the least squares method and summarized in Table 3. 


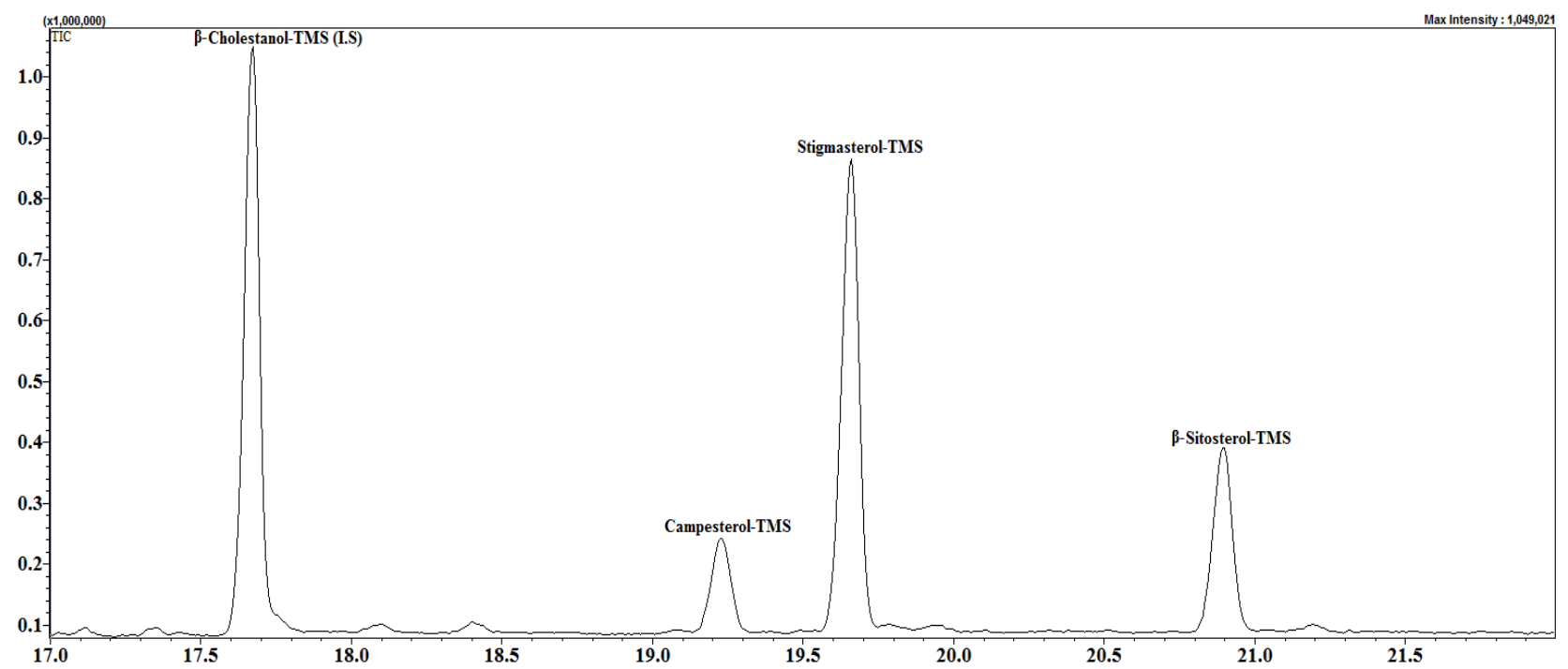

(A)

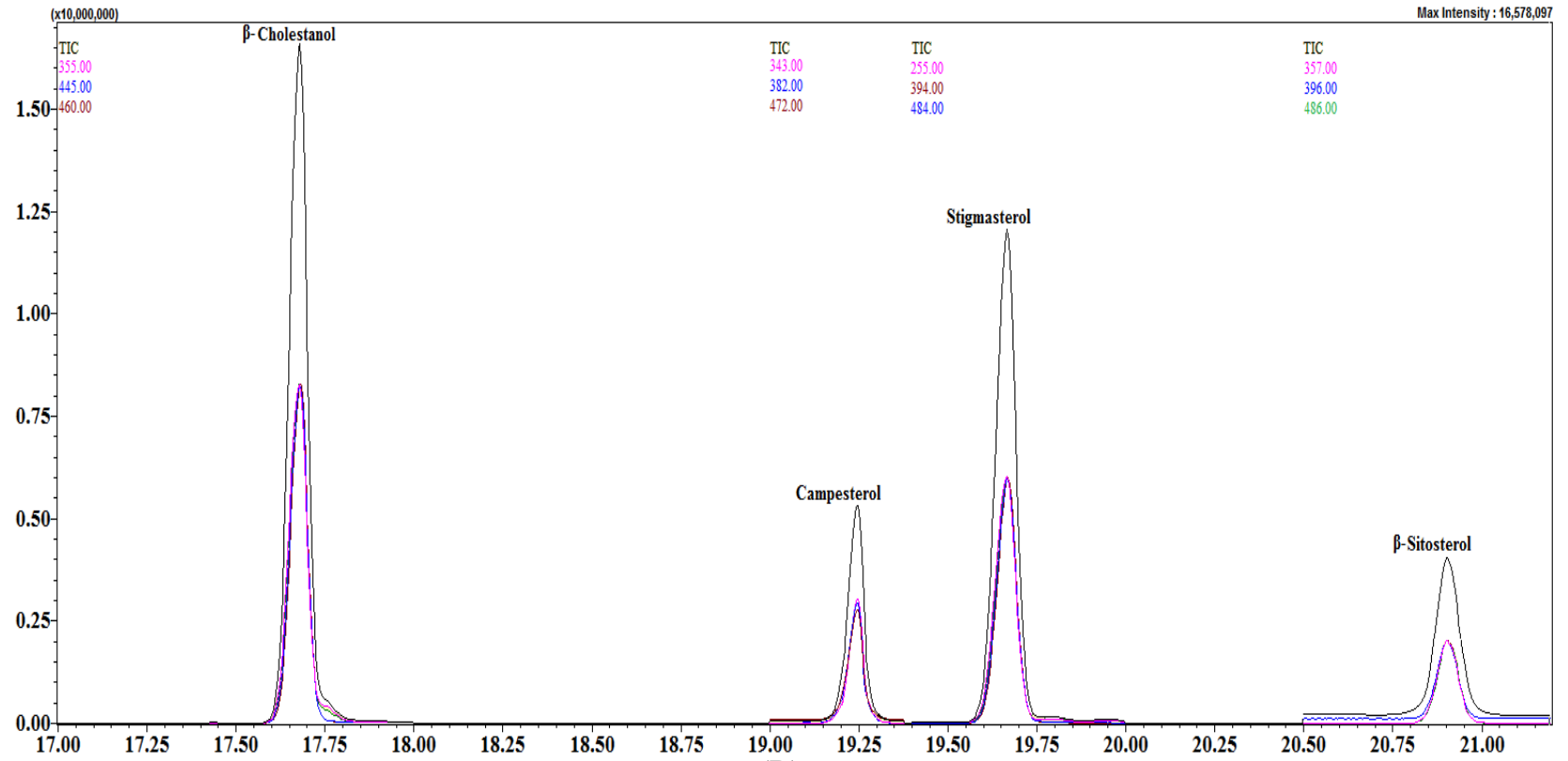

(B)

Figure 2 (A)Typical chromatogram of trimithylsilyl (TMS) ether derivatives of $\beta$-Cholestanol (I.S), campesterol, stigmasterol, and $\beta$-sitosterol at (5 mg L-1) using GC-MS-SCAN with split mode (50:1), (B) using GC-MS-SIM, (Rs $>2.0$, As $\leq 1.10$ and $\mathrm{N} \sim 175000$ ).

Table 2 Effect of derivatization temperature $\left({ }^{\circ} \mathrm{C}\right)$, time $(\mathrm{min})$ and reagent volume $(\mu \mathrm{L})$ on campesterol, stigmasterol and $\beta$-sitosterol concentrations ( $\mathrm{mg} \mathrm{kg}^{-1} \pm \mathrm{SD}$ ) of Adana 99 as selected Turkish bread sample.

\begin{tabular}{l|ccccc}
\hline \multicolumn{1}{c}{ Analyte } & $25^{\circ} \mathrm{C}$ & $40 \mathrm{C}$ & $50 \mathrm{C}$ & $60 \mathrm{C}$ & $70 \mathrm{C}$ \\
\hline Campesterol & $2.1 \pm 0.07$ & $4.9 \pm 0.39$ & $13.5 \pm 0.27$ & $16.5 \pm 0.31$ & $15.7 \pm 0.30$ \\
Stigmasterol & $0.9 \pm 0.01$ & $2.4 \pm 0.08$ & $5.8 \pm 0.07$ & $7.6 \pm 0.05$ & $7.0 \pm 0.03$ \\
$\beta$-sitosterol & $62.0 \pm 0.58$ & $140.9 \pm 1.78$ & $362.4 \pm 1.33$ & $419.7 \pm 1.51$ & $421.2 \pm 1.90$ \\
\hline & $15 \mathrm{~min}$ & $30 \mathrm{~min}$ & $45 \mathrm{~min}$ & $60 \mathrm{~min}$ & $90 \mathrm{~min}$ \\
Campesterol & $9.0 \pm 0.17$ & $16.3 \pm 0.34$ & $19.1 \pm 0.47$ & $21.4 \pm 0.34$ & $19.5 \pm 0.25$ \\
Stigmasterol & $4.1 \pm 0.02$ & $7.2 \pm 0.05$ & $8.7 \pm 0.03$ & $9.2 \pm 0.04$ & $8.1 \pm 0.02$ \\
$\beta$-sitosterol & $289.1 \pm 0.91$ & $417.1 \pm 1.18$ & $511.0 \pm 1.34$ & $580.5 \pm 1.74$ & $527.8 \pm 2.36$ \\
\hline & $10 \mu \mathrm{L}$ & $25 \mu \mathrm{L}$ & $50 \mu \mathrm{L}$ & $75 \mu \mathrm{L}$ & $100 \mu \mathrm{L}$ \\
Campesterol & $4.4 \pm 0.11$ & $6.8 \pm 0.46$ & $21.1 \pm 0.32$ & $21.3 \pm 0.28$ & $21.4 \pm 0.22$ \\
Stigmasterol & $2.0 \pm 0.01$ & $3.1 \pm 0.07$ & $9.0 \pm 0.09$ & $9.3 \pm 0.09$ & $9.4 \pm 0.08$ \\
$\beta$-sitosterol & $132.0 \pm 0.62$ & $183.5 \pm 1.51$ & $572.1 \pm 1.81$ & $578.3 \pm 1.53$ & $582.0 \pm 1.47$ \\
\hline
\end{tabular}


Table 3 Regression analysis of calibration curves for three plant sterols by proposed method.

\begin{tabular}{l|llllll}
\hline Plant sterol & $\mathrm{t}_{\mathrm{R}}$ (minutes) & Calibration Equation & $\mathrm{R}^{2}$ & $\mathrm{RSD} \%$ & $\mathrm{LOD}\left(\mathrm{mg} \mathrm{kg}^{-1}\right)$ & $\mathrm{LOQ}\left(\mathrm{mg} \mathrm{kg}^{-1}\right)$ \\
\hline Campesterol & $19.25 \pm 0.01$ & $\mathrm{y}=1.0714 \mathrm{x}+0.1068$ & 0.9979 & 0.55 & 0.054 & 0.165 \\
Stigmasterol & $19.67 \pm 0.01$ & $\mathrm{y}=0.6546 \mathrm{x}+0.0226$ & 0.9994 & 0.66 & 0.064 & 0.193 \\
$\beta$-Sitosterol & $20.90 \pm 0.01$ & $\mathrm{y}=0.1706 \mathrm{x}+0.0172$ & 0.9944 & 0.50 & 0.074 & 0.225 \\
\hline
\end{tabular}

$t_{R}$ retention time, $R^{2}$ : coefficient of determination, RSD: relative standard deviation, LOD: limit of detection, LOQ: limit of quantitation.

Table 4 Results of recovery efficiency of Plant sterols

\begin{tabular}{l|cccc}
\hline Plant sterol & Added $\left(\mathrm{mg} \mathrm{L}^{-1}\right)$ & Found \pm SD $\left(\mathrm{mg} \mathrm{L}^{-1}\right)$ & RSD \% & Recovery \% \\
\hline \multirow{3}{*}{$\beta$-Cholestanol } & 1.000 & $0.969 \pm 0.014$ & 1.35 & 96.87 \\
& 5.000 & $4.904 \pm 0.066$ & 1.31 & 98.08 \\
& 25.000 & $24.575 \pm 0.422$ & 1.71 & 98.30 \\
\hline \multirow{3}{*}{ Campesterol } & 1.000 & $0.919 \pm 0.015$ & 1.57 & 91.88 \\
& 5.000 & $4.878 \pm 0.059$ & 1.20 & 97.56 \\
\hline \multirow{3}{*}{ Stigmasterol } & 25.000 & $25.593 \pm 0.244$ & 0.95 & 102.37 \\
& 1.000 & $0.959 \pm 0.019$ & 1.75 & 95.90 \\
\hline \multirow{3}{*}{$\beta$-Sitosterol } & 5.000 & $4.969 \pm 0.087$ & 1.71 & 99.38 \\
& 25.000 & $25.814 \pm 0.349$ & 1.35 & 103.26 \\
\hline
\end{tabular}

SD: standard deviation $(n=4)$

The correlation coefficients were greater than $\geq$ 0.9944 with R.S.D $\leq 0.66$ and $R_{s}>2.0$ indicating a strong linear relationship between the variables. The results suggested that the developed GC-MS-SIM method has a linearity.

Sensitivity: LODs for campesterol, stigmasterol and $\beta$ sitosterol by GC-MS-SIM were lower $(0.054,0.064$, and $0.074 \mathrm{mg} \mathrm{kg}^{-1}$, respectively) compared with previous publications. Ahmida et al. (2006) reported that LODs of campesterol and $\beta$-sitosterol in human plasma using GCMS-SIM were 0.20 and $0.083 \mathrm{mg} \mathrm{kg}^{-1}$, respectively. Santos et al. (2007) reported that LODs of campesterol, stigmasterol and $\beta$-sitosterol in milk and yoghurt using GC-MS were $0.1 \mathrm{mg} \mathrm{kg}^{-1}$.

Accuracy (Recovery): The accuracy of method was performed to verify the effectiveness of the extraction step, and to exclude an incorrect quantification of plant sterols in Turkish bread wheat. The accuracy was achieved using the technique of external standard addition at three spiked levels $\left(1.00,5.00\right.$ and $\left.25.00 \mathrm{mg} \mathrm{L}^{-1}\right)$ with four replicate $(n=4)$. The results are summarized in Table 4.

Recovery was the highest with the highest addition (25 mg L ${ }^{-1}$ ) for $\beta$-cholestanol, campesterol, stigmasterol and $\beta$-sitosterol. The recovery was not influenced by the saponification temperature. The recovery ranges in this study for $\beta$-cholestanol (internal standard), campesterol, stigmasterol and $\beta$-sitosterol (96.87-98.30, 91.88-102.37, 95.90-103.26 and 91.66-104.99\%, respectively) are better than those reported by Phillips et al. (2005) for campesterol, stigmasterol and $\beta$-sitosterol (105, 100-118 and $102 \%$, respectively), by Ahmida et al. (2006) for $\beta$ cholestanol, campesterol and $\beta$-sitosterol (89.15-91.24, 83.33-94.13 and 94.93-98.20\%, respectively) and by Cunha et al. (2006) for campesterol, stigmasterol and $\beta$ sitosterol (61.6-95.4, 64.1-106.2 and 101.3-104.3\%, respectively), Thus, good recoveries with R.S.D lower than 2.25 were obtained for each of plant sterol confirming that the developed method was accurate.

Quantification of Plant Sterols in 20 Turkish Bread Wheat Cultivars.

The concentrations of campesterol, stigmasterol and $\beta$-sitosterol in 20 Turkish bread wheat cultivars were determined using GC-MS-SIM (Fig. 3).

The analysis of Turkish bread wheat cultivars grown in the same year and season will allow to compare them more accurately. Reference values for each plant sterol and standard deviations (with a confidence interval of 95\%) have reported in Table 5.

Table 5 shows that concentration ranges of campesterol, stigmasterol and $\beta$-sitosterol in 20 Turkish bread wheat cultivars were compared with similar previously published (Clifton et al., 2004; RuibalMendieta et al., 2004; Alignan et al., 2009; Nurmi et al., 2012). Relative standard deviations (RSD) were acceptable $(<6.1 \%)$. In this study we found that, stigmasterol, campesterol and $\beta$-sitosterol in 20 Turkish bread wheat cultivars ranged from ( 4.27 to $23.23,15.30$ to 76.02 and 303.21 to $682.00 \mathrm{mg} \mathrm{kg}^{-1}$, respectively). Toivo et al. (2000) reported that the concentration of stigmasterol, campesterol and $\beta$-sitosterol in wheat flour grown in Finland using GC-MS $\left(27,134\right.$ and $400 \mathrm{mg} \mathrm{kg}^{-1}$, respectively), Ruibal-Mendieta et al. (2004) reported that the concentration of stigmasterol, campesterol and $\beta$ sitosterol in winter wheat and spelt grown in Belgium using LC-MS (2.0-2.8, 113.3-145.3 and 349.6-394 $\mathrm{mg} \mathrm{kg}^{-1}$, respectively) for winter wheat and (1.7-3.6, 96.2-155.5 and $329-463 \mathrm{mg} \mathrm{kg}^{-1}$, respectively) for spelt, Alignan et al. (2009) reported that the concentration of stigmasterol, campesterol and $\beta$-sitosterol in selected bread wheat cultivars grown in France, Belgium and Italy using GC- 
FID (18-22, 98-121 and 337-410 $\mathrm{mg} \mathrm{kg}^{-1}$, respectively) and Nurmi et al. (2012) reported that the concentration of stigmasterol, campesterol and $\beta$-sitosterol in wheat grain which grown in German using RP-HPLC-UV (15, 115 and $362 \mathrm{mg} \mathrm{kg}^{-1}$, respectively).

From Table 5, it can be seen that there was a wide range of each main plant sterol concentration between 20 Turkish bread wheat cultivars which suggested that there some factors that have more effect on main plant sterols yield than the others such as elements content in soil.
As observed in the present study, a higher proportion of $\beta$-sitosterol (up to $682 \mathrm{mg} \mathrm{kg}^{-1}$ ) in Turkish bread wheat while a higher proportion of campesterol (up to $121 \mathrm{mg}$ $\mathrm{kg}^{-1}$ ) in French, Belgian and Italian bread wheat. On other hand a similar proportion of stigmasterol in most cases. These results suggest that the composition of plant sterols in Turkish bread wheat has a significantly higher lipid content, which increases its quality in comparison to French, Belgian and Italian bread wheat.

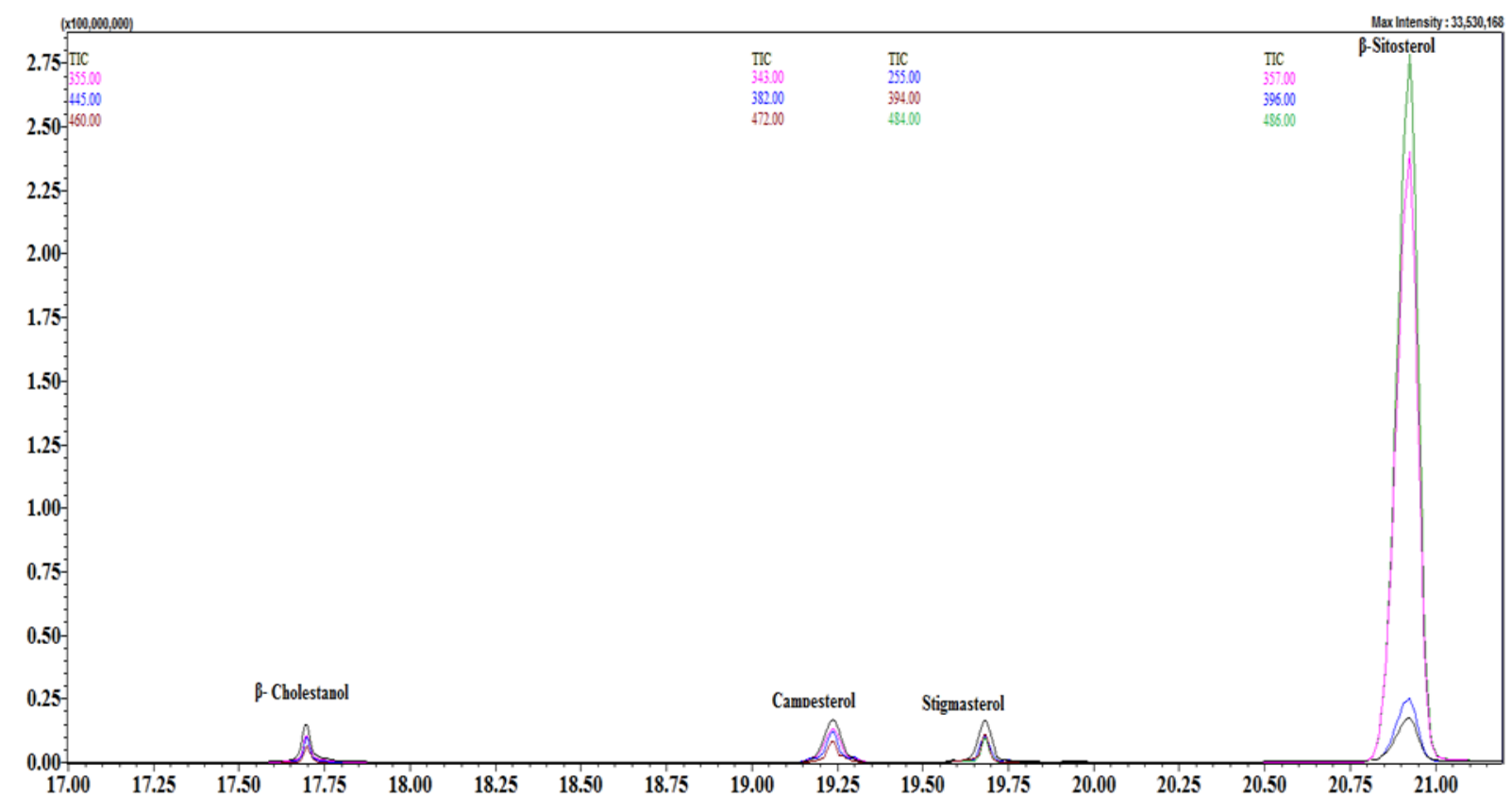

Figure 3 A typical GC-MS-SIM chromatogram of plant sterols found in Turkish bread wheat (Adana 99) with internal standard ( $\beta$-cholestanol, $5 \mathrm{mg} \mathrm{kg-1).}$

Table 5 Plant sterol contents $\left(\mathrm{mg} \mathrm{kg}^{-1}\right)$ of 20 Turkish bread wheat cultivars

\begin{tabular}{l|ccccc}
\hline \multirow{2}{*}{ Cultivar } & \multicolumn{2}{|c}{$\beta$-Cholestanol (I.S) } & \multicolumn{4}{c}{ Phytosterol } \\
\cline { 2 - 6 } Adana 99 & Added & Found \pm SD & Campesterol \pm SD & Stigmasterol \pm SD & $\beta$-Sitosterol \pm SD \\
Altınbaşak & 5.00 & $4.31 \pm 0.18$ & $21.43 \pm 0.19$ & $9.52 \pm 0.04$ & $581.50 \pm 1.32$ \\
Bayraktar & 5.00 & $4.69 \pm 0.09$ & $23.18 \pm 0.08$ & $6.78 \pm 0.03$ & $381.46 \pm 1.33$ \\
Bezostaja & 5.00 & $9.82 \pm 0.13$ & $18.24 \pm 0.06$ & $8.78 \pm 0.02$ & $338.87 \pm 1.86$ \\
Canik 2003 & 5.00 & $4.41 \pm 0.26$ & $24.50 \pm 0.18$ & $5.16 \pm 0.02$ & $359.94 \pm 1.42$ \\
Es 26 & 5.00 & $4.74 \pm 0.23$ & $28.12 \pm 0.27$ & $9.90 \pm 0.05$ & $392.87 \pm 2.79$ \\
Flamura 85 & 5.00 & $4.83 \pm 0.24$ & $37.38 \pm 0.10$ & $10.28 \pm 0.07$ & $417.64 \pm 1.59$ \\
Gökkan & 5.00 & $4.47 \pm 0.20$ & $24.36 \pm 0.25$ & $5.94 \pm 0.03$ & $383.67 \pm 1.30$ \\
Harmankaya & 5.00 & $4.71 \pm 0.18$ & $28.06 \pm 0.34$ & $9.47 \pm 0.03$ & $416.25 \pm 3.82$ \\
Karatoprak & 5.00 & $4.74 \pm 0.11$ & $27.60 \pm 0.22$ & $8.54 \pm 0.03$ & $453.54 \pm 3.52$ \\
Kiraç 66 & 5.00 & $4.35 \pm 0.15$ & $15.30 \pm 0.25$ & $4.27 \pm 0.04$ & $351.02 \pm 0.77$ \\
Mesut & 5.00 & $4.21 \pm 0.23$ & $36.55 \pm 0.33$ & $8.60 \pm 0.04$ & $540.52 \pm 1.75$ \\
Osmaniyem & 5.00 & $4.56 \pm 0.12$ & $50.53 \pm 0.48$ & $13.95 \pm 0.07$ & $586.10 \pm 1.74$ \\
Pandas & 5.00 & $4.45 \pm 0.17$ & $17.31 \pm 0.02$ & $4.37 \pm 0.02$ & $303.21 \pm 1.89$ \\
Sakin & 5.00 & $4.18 \pm 0.31$ & $36.26 \pm 0.14$ & $7.78 \pm 0.04$ & $356.62 \pm 2.40$ \\
Seri 2013 & 5.00 & $4.92 \pm 0.19$ & $51.47 \pm 0.24$ & $14.22 \pm 0.08$ & $614.10 \pm 0.89$ \\
Soyer & 5.00 & $4.86 \pm 0.36$ & $20.62 \pm 0.23$ & $8.05 \pm 0.04$ & $343.18 \pm 0.99$ \\
Sönmez & 5.00 & $4.91 \pm 0.13$ & $37.15 \pm 0.17$ & $9.66 \pm 0.06$ & $497.26 \pm 2.51$ \\
Tahirova & 5.00 & $4.64 \pm 0.22$ & $20.34 \pm 0.11$ & $6.31 \pm 0.04$ & $393.49 \pm 1.67$ \\
Yunus & 5.00 & $4.47 \pm 0.22$ & $34.38 \pm 0.24$ & $7.31 \pm 0.07$ & $514.66 \pm 1.33$ \\
\hline SD: & 5.00 & $4.90 \pm 0.23$ & $76.02 \pm 0.49$ & $23.23 \pm 0.09$ & $682.66 \pm 2.86$ \\
\hline
\end{tabular}




\section{Conclusions}

The present study is the first report examining the distribution and composition of main plant sterols in Turkish bread wheat. This method is able to ensure a high throughput with excellent power for separation of $\beta$ cholestanol (I.S), campesterol, stigmasterol and $\beta$ sitosterol in selected Turkish bread wheat cultivars by gas chromatography. Furthermore, SIM mode increases the specificity of analysis, eliminating the risk of an erroneous quantitative determination of main plant sterols, due to the co-elution of impurities. This implemented GC-MS-SIM method allowed to establish reference values for campesterol, stigmasterol and $\beta$ sitosterol in Turkish bread wheat which is an important step of this research in order to discriminate between twenty Turkish bread wheat cultivars.

\section{References}

Abidi SL. 2001. Chromatographic analysis of plant sterols in foods and vegetable oils. J Chromatogr A., 935: 173-201.

Ahmida HSM, Bertucci P, Franzo L, Massoud R, Cortese C, Lala A, Federici G. 2006. Simul-taneous determination of plasmatic phytosterols and cholesterol precursors using gas chromatography-mass spectrometry (GC-MS) with selective ion monitoring (SIM). J Chromatogr B., 842: 43-47.

Alignan M, Roche J, Bouniols A, Cerny M, Mouloungui Z, Merah O. 2009. Effects of ge-notype and sowing date on phytostanolphytosterol content and agronomic traits in wheat under organic agriculture. Food Chem., 117: 219-225.

Aydogan Cifci E, Yagdi K. 2012. Study Of Genetıc Diversity in Wheat (Triticum Aestivum) Varities using Random Amplified Polymorphic Dna (Rapd) Analysis. Turk J Field Crops., 17(1):91-95.

Breinholder P, Mosca L, Lindne W. 2002. Concept of sequential analysis of free and conjuga-ted phytosterols in different plant matrices. J Chromatogr B., 777: 67-82.

Cakmak I, Yilmaz A, Kalayci M, Ekiz H, Torun B, Erenoğlu B, Braun HJ. 1996. Zinc defici-ency as a critical problem in wheat production in Central Anatolia. Plant Soil., 180: 165-172.

Clifton PM, Noakes M, Sullivan D, Erichsen N, Ross D, Annison G, Fassoulakis A, Cehun M, Nestel P. 2004. Cholesterol-lowering effects of plant sterol esters differ in milk, yoghurt, bread and cereal. Eur J Clin Nutr., 58: 503-509.

Cunha SS, Fernandes JO, Oliveira MBPP. 2006. Quantification of free and esterified sterols in Portuguese olive oils by solid-phase extraction and gas chromatography mass spect-rometry. J Chromatogr A., 1128: 220-227.

Dulf FV, Bele C, Unguresan M, Parlog R, Socaciu C. 2009. Phytosterols as Markers in Identi-fication of the Adulterated Pumpkin Seed Oil with Sunflower Oil. Bulletin UASVM Agriculture., 66(2): 301-306.

Dutta PC, Appelqvist LA. 1997. Studies on Phytosterol Oxides. I: Effect of Storage on the Content in Potato Chips Prepared in Different Vegetable Oils. JAOCS., 74 (6): 647-657.

Dutta PC, Normen L. 1998. Capillary column gas-liquid chromatographic separation of $\Delta 5$-unsaturated and saturated phytosterols J Chromatogr A., 816: 177-184.

Egesel CÖ, Kahriman F, Tayyar Ş, Baytekin H. 2009. Interrelations of flour qua-lity traits with grain yield in bread wheat and choosing suitable cultivars. Anadolu J Agric Sci., 24(2): 76-83.

FAO (Food and Agriculture Organization of the United Nations). 2017. Country Brief Turkey, 1-2. (http://www.fao.org/ giews/countrybrief/country/TUR/pdf/TUR.pdf) [Accessed on 19.01.2017].
Francavilla M, Trotta P, Luque R. 2010. Phytosterols from Dunaliella tertiolecta and Dunali-ella salina: A potentially novel industrial application. Bioresour Technol., 101: 4144-4150.

Giray B, Girgin G, Basak Engin A, Aydın S, Sahin G. 2007. Aflatoxin levels in wheat samp-les consumed in some regions of Turkey. Food Control., 18: 23-29.

Grandgirard A, Martine L, Joffre C, Juaneda P, Berdeaux O. 2004. Gas chromatographic separation and mass spectrometric identification of mixtures of oxyphy-tosterol and oxycholesterol derivatives Application to a phytosterol-enriched food. J Chromatogr A., 1040: 239-250.

Imren M, Elekcioğlu IH, Özkan H. 2014. Determining the resistance of some bread wheat varieties against root lesion nematodes: pratylenchus thornei and pratylenchus neglec-tus (Tylenchida: Pratylenchidae). J Agr Sci., 21: 61-70.

Jeong WS, Lachance PA. 2001. Phytosterols and Fatty Acids in Fig (Ficus carica, var. Mis-sion) Fruit and Tree Components. Food Sci., 66: 278-281.

Jiang Y, Wang T. 2005. Phytosterols in Cereal by products. JAOCS., 82(6): 439-444.

Johnsson L, Andersson RE, Dutta, PC. 2003. Side-Chain Autoxidation of Stigmasterol and Analysis of a Mixture of Phytosterol Oxidation Products by Chromatographic and Spectroscopic Methods. JAOCS., 80(8): 777-783.

Kalo P, Kuuranne T. 2001. Analysis of free and esterified sterols in fats and oils by flash chromatography, gas chromatography and electrospray tandem mass spectrometry. J Chromatogr A., 935: 237-248.

Lagarda MJ, Garcia-Llatas G, Farre R. 2006. Analysis of phytosterols in foods. J Pharm Biomed Anal., 41: 1486-1496.

Mitei YC, Ngila JC, Yeboah SO, Wessjohann L, Schmidt J. 2009. Profiling of Phytosterols, Tocopherols and Tocotrienols in Selected Seed Oils from Botswana by GC-MS and HPLC. AOCS., 86: 617-625.

Moreau RA, Whitaker BD, Hicks KB. 2002. Phytosterols, phytostanols, and their conjuga-tes in foods: structural diversity, quantitative analysis, and healtpromoting uses. Prog. Lipid. Res., 41: 457-500.

Muller C, Staudacher V, Krauss J, Giera M. Bracher F. 2013. A convenient cellular assay or the identification of the molecular target of ergosterol biosynthesis inhibitors and qu-antification of their effects on total ergosterol biosynthesis. J Steroids., 78(5): 483-493.

Mut Z, Aydın N, Bayramoğlu HO , Özcan H. 2009. Interpreting Genotype Environment Interaction in Bread Wheat (Triticum aestivum L.) Genotypes Using Nonparametric Measures. Turk J Agric., 33: 127-137.

Nurmi T, Lampi AM, Nystrom L, Hemery Y, Rouau X, Pironen V. 2012. Distribution and composition of phytosterols and steryl ferulates in wheat grain and bran frac-tions. J Cereal Sci., 56: 379-388.

Phillips KM, Ruggio DM, Ashraf-Khorassni M. 2005. Phytosterol Composition of Nuts and Seeds Commonly Consumed in the United States. J Agric Food Chem., 53: 9436-9445.

Rozenberg R, Ruibal-Mendieta NL, Petitjean G, Cani P, Delacroix DL, Delzenne NM, Meu-rens M, Quetin-Leclercq J, HabibJiwan JL. 2003. Phytosterol analysis and characteri-zation in spelt (Triticum aestivum ssp. spelta L.) and wheat (T. aestivum L.) lipids by LC/APCI-MS. J Cereal Sci., 38: 189-197.

Ruibal-Mendieta NL, Rozenberg R, Delacroix DL, Petitjean G, Dekeyser A, Baccelli C, Marques C, Delzenne NM, Meurens M, Habib-Jiwan JL, Quetin-Leclercq J. 2004. Spelt (Triticum spelta L.) and Winter Wheat (Triticum aestivum L.) Wholemeals Have Similar Sterol Profiles, As Determined by Quantitative Liquid Chromatography and Mass Spectrometry Analysis. J Agric Food Chem., 52: 4802-4807.

Sankalia JM, Sankalia MG, Sutariya VB, Mashru RCJ. 2007. Nateglinide quantifi-cation in rabbit plasma by HPLC: Optimization and application to phar-macokinetic study. J Pharm Biomed Anal., 44: 196-204. 
Santos R, Limas E, Sousa M, Conceicao-Castilho M, Ramos F, Silveira MIN. 2007. Optimization of analytical procedures for GC-MS determination of phytosterols and phytostanols in enriched milk and yoghurt. Food Chem., 102: 113-117.

Shewry PR. 2009. Wheat. J Exp Bot., 60 (6): 1537-1553.

Song D, Wang J. 2003. Modified resolution factor for asymmetrical peaks in chromatographic separation. J Pharm Biomed Anal., 32, 1105-1112.

Toivo J, Lampi AM, Aalto S, Piironen V. 2000. Factors affecting sample preparation in the gas chromatographic determination of plant sterols in whole wheat flour. Food Chem., 68: 239-245.

USDA (United States Department of Agriculture), Foreign Agriculture service. 2016. Turkey Grain and Feed Annual Report. Grain and Feed Annual., TR6015, 1-35.

Valsta LM, Lemstrom A, Ovaskainen M L, Lampi AM, Toivo J, Korhonen T, Piironen V. 2004. Estimation of plant sterol and cholesterol intake in Finland:Quality of new va-lues and their effect on intake. Br J Nutr., 92(4): 671-678.
Wang M, Qu F, Shan XQ, Lin JM. 2003. Development and optimization of a method for the analysis of low-molecularmass organic acids in plants by capillary electrophoresis with indirect UV detection. J Chromatogr A., 989: 285-292.

Yiğit, A. 2015. Determination of protein, aminoacid distribution and antioxidant activity of widely grown bread wheat (Triticum aestivum L.) varieties in Turkey. M. Sc. Thesis, Adnan Menderes university, Turkey (http://adudspace.adu.edu.tr: 8080/jspui/bitstream/11607/1550/3/10062758.pdf] [Accessed on 13.01.2015].

Yildirim M, Ildirim BN, Çakmak M, Belen S. 2012. Diallel $(5 \times 5)$ analysis on mixtures of some white kernelled wheat varieties. Gümüşhane University Journal of Science and Technology Institute., 2(1): 49-54. 